Article

\title{
Comprehensive Analysis of RNA-Seq Gene Expression Profiling of Brain Transcriptomes Reveals Novel Genes, Regulators, and Pathways in Autism Spectrum Disorder
}

\author{
Md Rezanur Rahman 1,2 ${ }^{\mathbb{D}}$, Maria Cristina Petralia ${ }^{3}$, Rosella Ciurleo $^{3}$, Alessia Bramanti ${ }^{3}$, \\ Paolo Fagone ${ }^{4}\left(\mathbb{D}\right.$, Md Shahjaman ${ }^{5}$, Lang Wu ${ }^{6}$, Yanfa Sun 6,7,8 (D), Beste Turanli 9 (D), \\ Kazim Yalcin Arga ${ }^{9}$ (D), Md Rafiqul Islam 10,11, Tania Islam ${ }^{1}$ (D) and Ferdinando Nicoletti ${ }^{4, *}$ (D) \\ 1 Department of Biotechnology and Genetic Engineering, Faculty of Biological Sciences, Islamic University, \\ Kushtia 7003, Bangladesh; rezanur12@yahoo.com (M.R.R.); taniaislam1304@gmail.com (T.I.) \\ 2 Department of Biochemistry and Biotechnology, Khwaja Yunus Ali University, Enayetpur, \\ Sirajganj 6751, Bangladesh \\ 3 IRCCS Bonino-Pulejo, 98123 Messina, Italy; m.cristinapetralia@gmail.com (M.C.P.); \\ rossella.ciurleo@irccsme.it (R.C.); alessia.bramanti@irccsme.it (A.B.) \\ 4 Department of Biomedical and Biotechnological Sciences, University of Catania, 95124 Catania CT, Italy; \\ paolofagone@yahoo.it \\ 5 Department of Statistics, Begum Rokeya University, Rangpur 5404, Bangladesh; shahjaman_brur@yahoo.com \\ 6 Cancer Epidemiology Division, Population Sciences in the Pacific Program, University of Hawaii Cancer \\ Center, University of Hawaii at Manoa, Honolulu, HI 96813, USA; lwu@cc.hawaii.edu (L.W.); \\ ysun@cc.hawaii.edu (Y.S.) \\ 7 College of Life Science, Longyan University, Longyan 364000, China \\ 8 Fujian Provincial Key Laboratory for the Prevention and Control of Animal Infectious Diseases and \\ Biotechnology, Longyan 364000, China \\ 9 Department of Bioengineering, Marmara University, Istanbul 34722, Turkey; \\ beste.turanli@marmara.edu.tr (B.T.); kazim.arga@marmara.edu.tr (K.Y.A.) \\ 10 School of Biomedical Sciences, Faculty of Health, Institute of Health and Biomedical Innovation, \\ Queensland University of Technology (QUT), Brisbane 4059, QLD, Australia; rafiqulislambd7@gmail.com \\ 11 Department of Pharmacy, Faculty of Biological Science and Technology, Jashore University of Science and \\ Technology, Jashore 7408, Bangladesh \\ * Correspondence: ferdinic@unict.it
}

Received: 17 September 2020; Accepted: 14 October 2020; Published: 17 October 2020

\begin{abstract}
Background: Autism spectrum disorder (ASD) is a neurodevelopmental disorder with deficits in social communication ability and repetitive behavior. The pathophysiological events involved in the brain of this complex disease are still unclear. Methods: In this study, we aimed to profile the gene expression signatures of brain cortex of ASD patients, by using two publicly available RNA-seq studies, in order to discover new ASD-related genes. Results: We detected 1567 differentially expressed genes (DEGs) by meta-analysis, where 1194 were upregulated and 373 were downregulated genes. Several ASD-related genes previously reported were also identified. Our meta-analysis identified 235 new DEGs that were not detected using the individual RNA-seq studies used. Some of those genes, including seven DEGs (PAK1, DNAH17, DOCK8, DAPP1, PCDHAC2, and ERBIN, $S L C 7 A 7)$, have been confirmed in previous reports to be associated with ASD. Gene Ontology (GO) and pathways analysis showed several molecular pathways enriched by the DEGs, namely, osteoclast differentiation, TNF signaling pathway, complement and coagulation cascade. Topological analysis of protein-protein interaction of the ASD brain cortex revealed proteomics hub gene signatures: $M Y C$, TP53, HDAC1, CDK2, BAG3, CDKN1A, GABARAPL1, EZH2, VIM, and TRAF1. We also identified the transcriptional factors (TFs) regulating DEGs, namely, FOXC1, GATA2, YY1, FOXL1, USF2, NFIC,
\end{abstract}


NFKB1, E2F1, TFAP2A, HINFP. Conclusion: Novel core genes and molecular signatures involved with ASD were identified by our meta-analysis.

Keywords: autisms spectrum disorders; meta-analysis; RNA-sequencing; transcriptomes; protein-protein interaction; molecular pathways

\section{Introduction}

Autism spectrum disorder (ASD) is a severe neurodevelopmental disorder that limits communication, social interactions, and repetitive behaviors are observed in ASD-affected people. There is no cure for this disease yet. The Centers for Disease Control (CDC) has reported that 1 in 54 children has ASD in the US, according to Autism and Developmental Disabilities Monitoring (ADDM) Network (Data published in 2016) [1]. The pattern of prevalence of ASD has been predicted to rise in the coming years. The pathophysiological mechanisms of ASD are very complex and multiple etiological processes are involved. Although genetic heritability is considered to be the principal cause of the disease, various immunological, neurological and environmental factors are involved in ASD. The pathophysiology of non-genetic forms of ASD has yet to be determined. Thus, identification of specific genes and molecular pathways is an unmet challenge, which will uncover potential mechanisms and new avenues to the development of treatment targets for ASD.

Changes in gene expression are widely studied to characterize various human diseases and successfully used to predict molecular and cellular processes in complex diseases [2,3]. Recently, some studies have been focused ASD pathogenesis to decode gene expression signatures specific for ASD. Previous studies found that several candidate genes demonstrated differential expression of ASD patients in brain and blood, as compared to healthy controls [4-9]. Despite some important data having been obtained from previous analyses $[4,10]$, we here applied a System Biology approach to further deepen the understanding of the pathophysiological mechanisms in ASD. In this study, two independent publicly available ASD brain studies were used to perform a meta-analysis aimed at identifying novel ASD candidate genes. Additionally, functional enrichment, protein-protein interaction, DEGs-transcription factors, and diseasome analyses were carried out to shed light on potential mechanisms of ASD pathogenesis.

\section{Materials and Methods}

\subsection{Acquisition of the Transcriptomics Data}

We searched the big transcriptomics database Gene Expression Omnibus (GEO) in March 2020 to collect the RNA-Seq datasets of human ASD brain samples [11]. We focused on human RNA-Seq data. The criteria used for the selection of the datasets were: (1) human RNA-Seq data of brain cortex; (2) complete raw gene expression count data; (3) the tissues should be from the brain cortex; (4) excluded non-human samples. The detailed procedures are described in Figure 1. Finally, two RNA-Seq transcriptomics datasets from ASD brain cortex region were chosen for this study. The description and characteristics of the data are presented in Table 1. The GSE64018 included transcriptomes from post-mortem brain tissues from 12 ASD and 12 healthy controls, that were age and sex matched. The brain samples from superior temporal gyrus representing Brodmann areas BA41/42/22 were dissected, without harming the gray matter, from all cortical layers. The GSE30573 dataset contains gene expression profiling of post-mortem brain tissues from three ASD samples and three healthy controls from the brain cortex. The detailed demographic data of the samples included in this study is presented in Supplementary Tables S1 and S2. 


\section{Literature review and data collection}

- Human RNA-Seq transcriptomics data of Autism spectrum disorder from Gene Expression Omnibus

\section{4 datasets}

\section{Data filtering}

- Human RNA-Seq data of cortical brain

- Complete raw gene expression count data

-Excluded a RNA-Seq dataset contained non-human control

\section{2 datasets}

\section{Data processing}

-RNA-Seq dataset was analyzed in R

- Differential expression analysis for individual studies in DESeq2

\section{Statistical meta-analysis}

-Meta-analysis of RNA-Seq studies by metaRNAseq to identify differential expression of genes (DEGs)

\section{Visualization and functional interpretation}

- Gene PPI analysis were performed in NetworkAnalyst

- Ontology (GO) terms and molecular pathways analysis

- Gene-transcription factors interaction network analysis

-Cross-validation of genes with know Autism gene database

- Gene-diseasome interaction network analysis

Figure 1. Workflow of data selection and meta-analysis. The Gene Expression Omnibus was searched for human post-mortem RNA-Seq gene expression profiling datasets of brain cortex from autism spectrum disorder patients. Functional analysis was performed on the data obtained from the meta-analysis of the selected datasets. 
Table 1. Characteristics of datasets employed in the study.

\begin{tabular}{ccc}
\hline GEO Accession & Brain & No of Sample \\
\hline \multirow{2}{*}{ GSE64018 } & cortex & Control: 12 \\
& ASD:12 \\
\hline \multirow{2}{*}{ GSE30573 } & cortex & Control: 3 \\
& & ASD: 3 \\
\hline
\end{tabular}

GEO: Gene Expression Omnibus.

\subsection{Data Processing and Differential Expression Analysis of Individual Datasets}

The differential expression of individual RNA-Seq dataset was analyzed in R using the package DESeq2 [12]. We used the filtering criteria to include genes that based on the mean of normalized counts as the filter statistic using independent filtering function in DESeq2 with default parameters. We used MetaRNASeq [13] package to perform Fisher's combined probability test for meta-analysis. Fisher's combination of $p$-values from independent datasets are combined via the following formula $[13,14]$ :

$$
F_{g}=-2 \sum_{t=1}^{T} \ln \left(P_{g t}\right)
$$

where $P_{g t}$ is the raw $p$-value obtained from gth gene for study t. For independent $p$-values the values of $F_{g}$ lies between 0 to $+\infty$ and it follows Chi-squared distribution with $2 T$ degrees of freedom. It produces larger values corresponding to smaller values of $P_{g t}$ and smaller values corresponding to larger values of $P_{g t}$. Therefore, the larger values of $F_{g}$ indicates the rejection of null hypothesis. $p$-values were adjusted by Benjamini-Hochberg false discovery rate (FDR).

\subsection{Functional Enrichment Analysis}

Functional annotation of the identified differentially expressed genes was performed using the clusterprofiler $\mathrm{R}$ package [15]. An adjusted $p$-value $<0.05$ was considered for the selection of the enriched Gene Ontology (GO) terms and pathways.

\subsection{Protein-Protein Interaction Analysis}

We built a brain protein-protein interactome (PPI) network of the proteins encoded by the DEGs using NetworkAnalyst-an online web tool for data analysis and visualization [16]. The zero-order network was constructed. The hub proteins were selected based on a degree $>15$.

\subsection{Transcriptional Regulators of the DEGs}

The network of interactions between DEGs-TFs was constructed using JASPAR database built in NetworkAnalyst [16]. The top 10 identified TFs were considered as principal transcriptional regulators of DEGs.

\subsection{In Silico Cross-Validation and Gene Disease Association Network Analyses}

We cross-checked the identified DEGs found in our meta-analysis with data from SFARI Gene 2.0, a community-driven knowledgebase for the autism spectrum disorders [17]. A gene-disease association network was also built using the DisGeNet database [18], implemented in NetworkAnalyst. DisGeNET is a wide database comprising links from numerous sources that include the complex biological features of disorders. Gene-disorder interaction with specific DEGs was analyzed via a NetworkAnalyst to identify related disease and chronic conditions. Top pathways were detected based on degree measure [19]. 


\section{Results}

\subsection{Detection of Differentially Expressed Genes in Brain Cortex via Meta-Analysis of RNA-Seq Transcriptomics}

We investigated the gene expression profile of the brain cortex of 15 ASD cases and 15 controls (Table 1, Tables S1 and S2). The ASD gene expression profile was obtained by performing a meta-analysis of the selected RNA-Seq studies. Based on the chosen statistical criteria-adjusted $p$-value $<0.05$ and $\log 2 \mathrm{FC} \geq 1$-we detected 1567 differentially expressed genes (DEGs), with 373 downregulated and 1194 upregulated genes in ASD compared to controls (Table S3). The counts of the common genes shared among individual studies/dataset and the meta-analysis are shown as Venn diagram (Figure 2). We identified 65 DEGs that were already known to be causal genes in ASD, from the SFARI autism research database. Among the DEGs identified in the meta-analysis, 235 DEGs were not identified by the analysis of the individual datasets. The top 50 DEGs, sorted by $p$-value, are presented in Table 2. Among these DEGs, seven overlapped with already known causal genes in ASD.

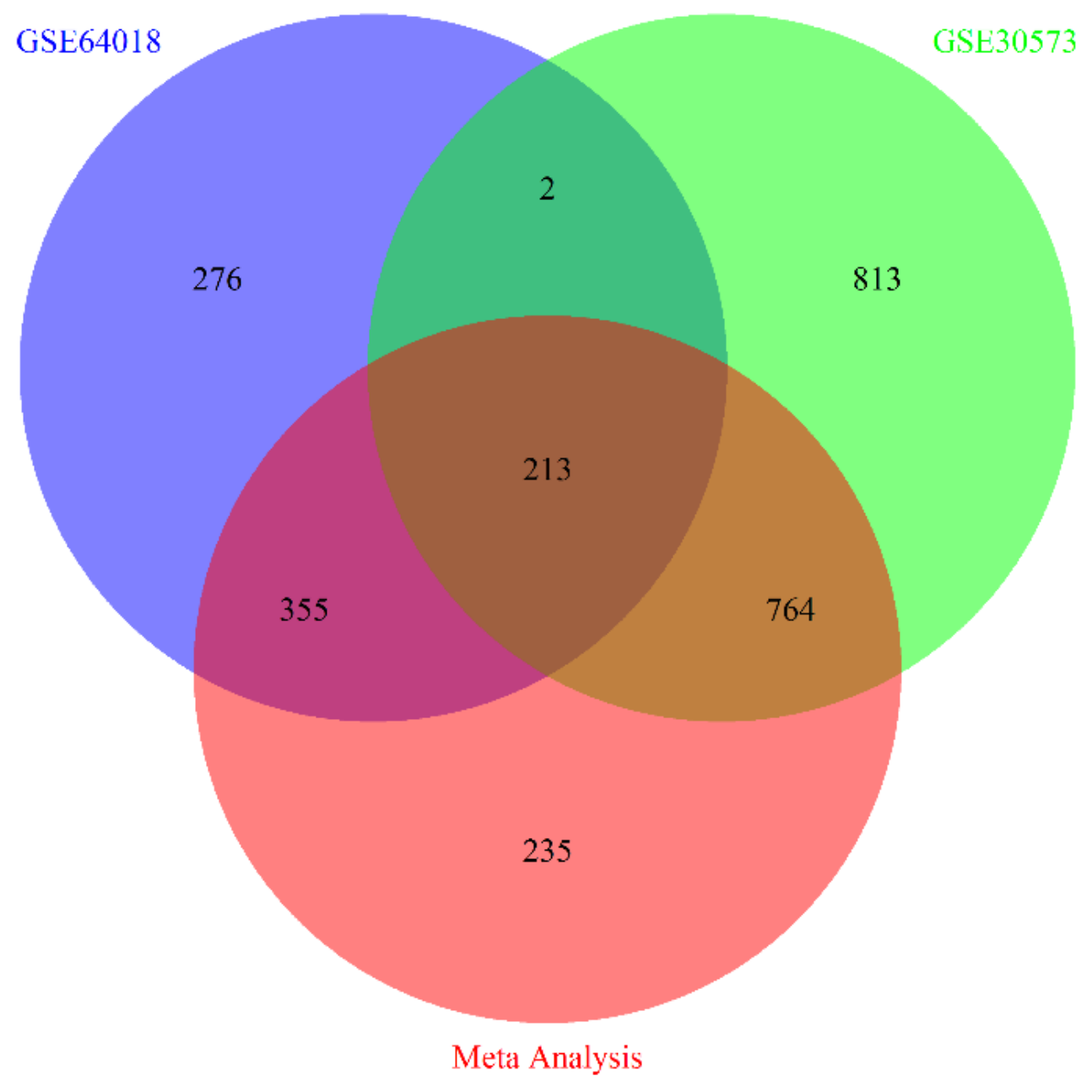

Figure 2. Venn diagram showing the number of differential expressed genes from individual studies and meta-analysis. 
Table 2. Newly differentially expressed genes newly identified in the meta-analysis.

\begin{tabular}{|c|c|c|c|c|}
\hline Ensemble ID & Gene Symbol & FDR & Average $\log _{2} \mathrm{FC}$ & Regulation of Direction \\
\hline ENSG00000077420 & APBB1IP & 5.92E-06 & 1.02 & Upregulated \\
\hline ENSG00000134516 & DOCK2 & $6.38 \mathrm{E}-05$ & 1.07 & Upregulated \\
\hline ENSG00000142102 & PGGHG & 0.000223 & 1.06 & Upregulated \\
\hline ENSG00000146192 & FGD2 & 0.000394 & 1.27 & Upregulated \\
\hline ENSG00000142583 & $S L C 2 A 5$ & 0.000449 & 1.31 & Upregulated \\
\hline ENSG00000188282 & RUFY4 & 0.000537 & 2.67 & Upregulated \\
\hline ENSG00000053918 & KCNQ1 & 0.000553 & 1.11 & Upregulated \\
\hline ENSG00000123338 & NCKAP1L & 0.000703 & 1.15 & Upregulated \\
\hline ENSG00000107099 & DOCK8 & 0.000823 & 1.04 & Upregulated \\
\hline ENSG00000249825 & AC012636.1 & 0.001274 & 1.21 & Upregulated \\
\hline ENSG00000128602 & SMO & 0.001487 & 1.19 & Upregulated \\
\hline ENSG00000213694 & S1PR3 & 0.001625 & 1.06 & Upregulated \\
\hline ENSG00000184574 & LPAR5 & 0.001879 & 1.25 & Upregulated \\
\hline ENSG00000198142 & SOWAHC & 0.002218 & 1.07 & Upregulated \\
\hline ENSG00000197324 & LRP10 & 0.002269 & 1.22 & Upregulated \\
\hline ENSG00000104903 & LYL1 & 0.002295 & -1.01 & Upregulated \\
\hline ENSG00000152192 & POU4F1 & 0.002449 & 3.19 & Upregulated \\
\hline ENSG00000188511 & C22orf34 & 0.002528 & 1.09 & Upregulated \\
\hline ENSG00000132561 & MATN2 & 0.003122 & 1.00 & Upregulated \\
\hline ENSG00000137767 & SQOR & 0.003406 & 1.14 & Upregulated \\
\hline ENSG00000178623 & GPR35 & 0.003868 & 1.10 & Upregulated \\
\hline ENSG00000137693 & YAP1 & 0.004274 & 1.18 & Upregulated \\
\hline ENSG00000187554 & TLR5 & 0.004764 & 1.05 & Upregulated \\
\hline ENSG00000155465 & SLC7A7 & 0.005133 & 1.10 & Upregulated \\
\hline ENSG00000092531 & SNAP23 & 0.005308 & 1.03 & Upregulated \\
\hline ENSG00000183508 & TENT5C & 0.005427 & 1.61 & Upregulated \\
\hline ENSG00000136732 & GYPC & 0.005534 & 1.03 & Upregulated \\
\hline ENSG00000258701 & LINC00638 & 0.005609 & 1.23 & Upregulated \\
\hline ENSG00000158516 & CPA2 & 0.005742 & 2.25 & Upregulated \\
\hline ENSG00000135245 & HILPDA & 0.006065 & 1.25 & Upregulated \\
\hline ENSG00000125398 & SOX9 & 0.006225 & 1.24 & Upregulated \\
\hline ENSG00000142512 & SIGLEC10 & 0.006448 & 1.31 & Upregulated \\
\hline ENSG00000105137 & SYDE1 & 0.006757 & 1.05 & Upregulated \\
\hline ENSG00000084093 & REST & 0.006965 & 1.20 & Upregulated \\
\hline ENSG00000167393 & PPP2R3B & 0.007156 & 1.02 & Upregulated \\
\hline ENSG00000174348 & PODN & 0.007183 & 1.08 & Upregulated \\
\hline ENSG00000143384 & MCL1 & 0.007261 & 1.05 & Upregulated \\
\hline ENSG00000231327 & LINC01816 & 0.007409 & 1.07 & Upregulated \\
\hline ENSG00000168209 & DDIT4 & 0.007787 & 1.04 & Upregulated \\
\hline ENSG00000127418 & FGFRL1 & 0.007833 & 1.05 & Upregulated \\
\hline ENSG00000225032 & AL162586.1 & 0.008133 & 1.14 & Upregulated \\
\hline ENSG00000101916 & TLR8 & 0.008409 & 2.09 & Upregulated \\
\hline ENSG00000155926 & SLA & 0.008477 & 1.07 & Upregulated \\
\hline ENSG00000121933 & TMIGD3 & 0.008491 & 1.16 & Upregulated \\
\hline
\end{tabular}


Table 2. Cont.

\begin{tabular}{ccccc}
\hline Ensemble ID & Gene Symbol & FDR & Average $\log _{2}$ FC & Regulation of Direction \\
\hline ENSG00000205336 & ADGRG1 & 0.008543 & 1.04 & Upregulated \\
\hline ENSG00000101057 & MYBL2 & 0.0087 & 3.23 & Upregulated \\
\hline ENSG00000165806 & CASP7 & 0.008879 & 1.09 & Upregulated \\
\hline ENSG00000223764 & LINC02593 & 0.008879 & 1.67 & Upregulated \\
\hline ENSG00000104689 & TNFRSF10A & 0.009434 & 1.10 & Upregulated \\
\hline ENSG00000225684 & FAM225B & 0.009746 & 1.62 & Upregulated \\
\hline
\end{tabular}

FDR: False Discovery Rate; FC: Fold Change.

\subsection{Data Visualization and Functional Interpretation}

To decipher the biological involvement and the potential molecular mechanisms underlying the pathogenesis of ASD, we performed GO and Pathway analysis on the DEGs. The GO analyses showed biological process (BP) in the ASD cortex were mainly involved in inflammatory response and immune systems, in particular, regulation of leukocyte activation, leukocyte migration, neutrophil degranulation, and leukocyte migration (Figure 3A). The cellular components encoded by the DEGs were mainly extracellular matrix, secretory granule membrane, presynapse (Figure 3A). The mainly molecular functions (MF) were glycosaminoglycan binding, heparin binding, cytokine activity, ion gated channel activity enriched by the DEGs (Figure 3A).
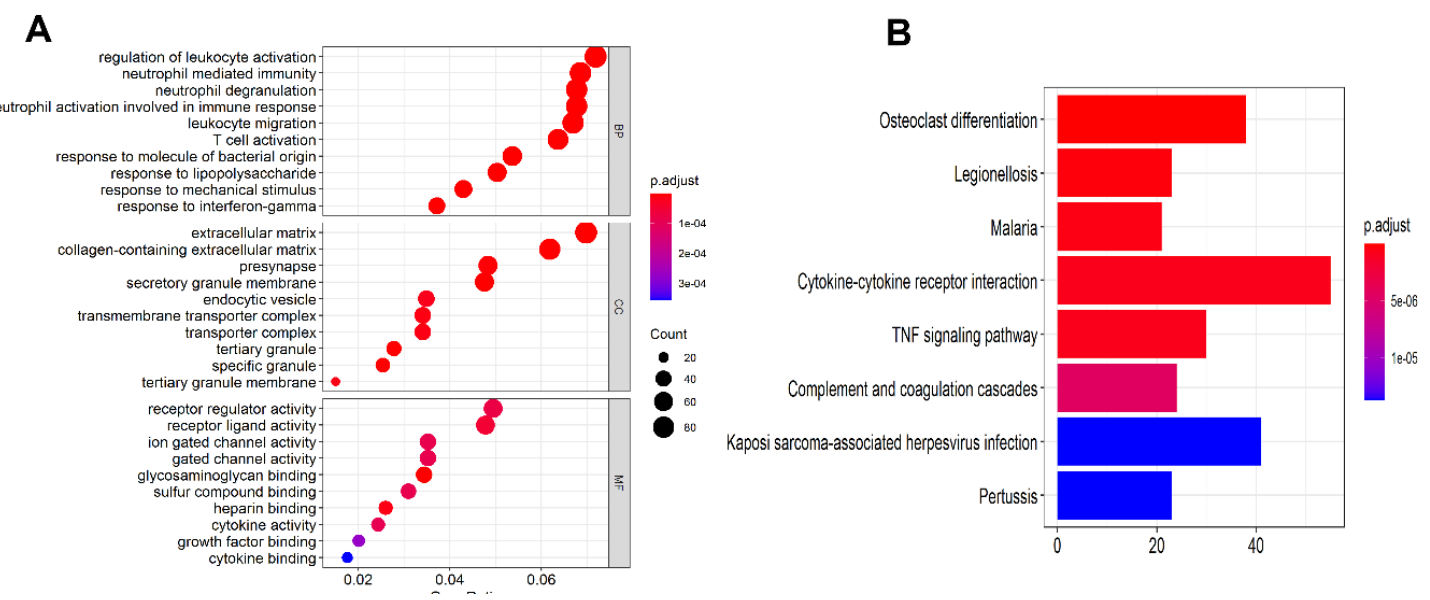

Figure 3. (A) Dot plot showing the Gene Ontology (biological process, cellular process, molecular function) analysis for the differentially expressed genes (DEGs) identified in the meta-analysis. Dots are color-coded from blue to red based on the adjusted $p$-value. The size of the dots is proportional to gene count. (B) Bar plot shows KEGG molecular pathways enriched by the DEGs ( $p$-value $<0.05$ ). Bars are color-coded from blue to red based on the adjusted $p$-value.

The pathway analyses revealed that osteoclast differentiation, cytokine-cytokine receptor interaction, TNF signaling pathway, complement and coagulation cascade, pertussis, malaria, legionellosis, Kaposi sarcoma-associated herpesvirus infection were significantly enriched among the DEGs, as shown in Figure 3B.

\subsection{Hub Proteins: Protein Interactome Analysis}

We performed brain protein-protein interaction analysis of the DEGs identified by the meta-analysis using the brain (cortex) protein interactome data. We reconstructed a subnetwork around DEGs encoded protein in dataset or tissue (Figure 4). The first order subnetwork built using DEGs had 6231 nodes and 15,330 edges contained 946 seed nodes. Then, a zero-order network was reconstructed 
which had 471 nodes, 760 edges and 471 seeds (Figure 4). The degree-based topological analysis of the network revealed 10 hub genes (MYC, TP53, HDAC1, CDK2, BAG3, CDKN1A, GABARAPL1, EZH2, VIM, and TRAF1). Table 3 shows the details topological parameters, roles, and molecular significance of the hub proteins.

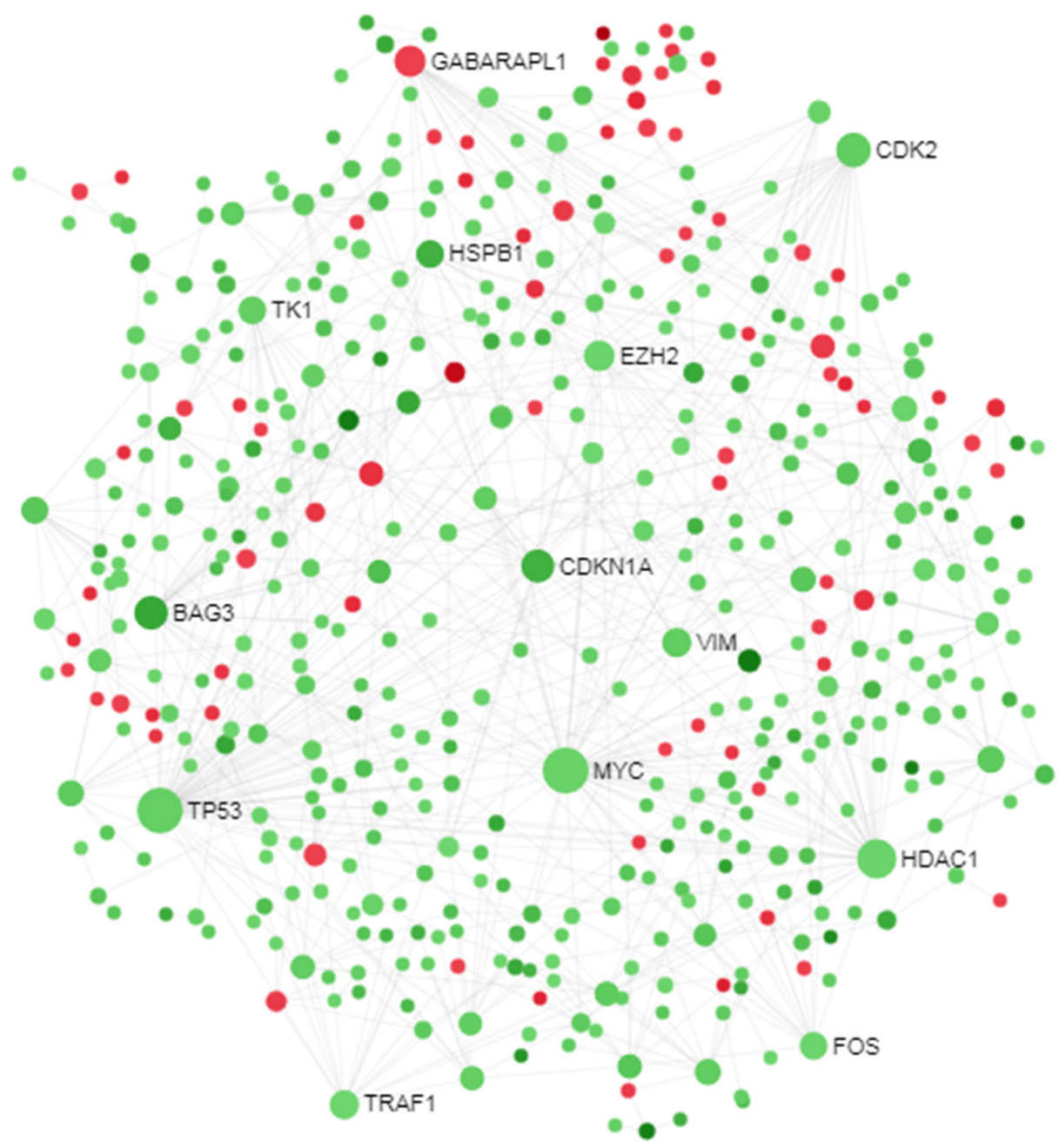

Figure 4. PPI subnetwork analysis of differentially expressed genes (DEGs). Circles represent nodes and grey lines represent interaction partners of the DEGs. The green nodes represent upregulated DEGs, while the red nodes represent downregulated DEGs.

Table 3. Hub proteins identified from protein-protein interaction network analysis of corresponding proteins encoded by the differentially expressed genes obtained in the meta-analysis.

\begin{tabular}{|c|c|c|c|c|c|}
\hline Gene Symbol & Description & Regulation & Degree & Biological Significance & Reference \\
\hline$B A G 3$ & BAG cochaperone 3 & Up & 23 & Parkinson's disease & [20] \\
\hline CDK2 & Cyclin dependent kinase 2 & $\mathrm{Up}$ & 25 & Involved in cell cycle regulation & GeneCard \\
\hline CDKN1A & $\begin{array}{l}\text { Cyclin dependent kinase } \\
\text { inhibitor } 1 \mathrm{~A}\end{array}$ & Up & 22 & $\begin{array}{l}\text { Implicated in ASD in dorsolateral } \\
\text { prefrontal cortex region of brain }\end{array}$ & [21] \\
\hline $\mathrm{EZH} 2$ & $\begin{array}{l}\text { Enhancer of zeste } 2 \\
\text { polycomb repressive } \\
\text { complex } 2 \text { subunit }\end{array}$ & Up & 18 & $\begin{array}{l}\text { Genetic variation of EZH2-a } \\
\text { chromatin remodeling factors is } \\
\text { observed in intellectual } \\
\text { disabilities and ASD; EZH2 in } \\
\text { human embryonic brain } \\
\text { suggesting a contributory role of } \\
\text { this gene in etiology of ASD in } \\
\text { Chinese population }\end{array}$ & {$[22,23]$} \\
\hline
\end{tabular}


Table 3. Cont.

\begin{tabular}{cccccc}
\hline Gene Symbol & Description & Regulation & Degree & Biological Significance & Reference \\
\hline HDAC1 & Histone Deacetylase 1 & $\mathrm{Up}$ & 35 & $\begin{array}{c}\text { Several studies have suggested a } \\
\text { role for HDAC1 and HDAC2 in } \\
\text { learning and memory behaviors }\end{array}$ & [24] \\
\hline GABARAPL1 & $\begin{array}{c}\text { GABA Type A Receptor } \\
\text { Associated Protein Like 1 }\end{array}$ & Down & 19 & ASD associated pathway & [25] \\
\hline MYC & MYC proto-oncogene & $\mathrm{Up}$ & 54 & $\begin{array}{c}\text { Implicated in tumorigenesis and } \\
\text { metabolism }\end{array}$ \\
\hline TRAF1 & TNF receptor associated & $\mathrm{Up}$ & 16 & $\begin{array}{c}\text { Involved in inflammation and } \\
\text { aberrant expression leads to } \\
\text { inflammatory disease }\end{array}$ \\
\hline factor 1 & Vimentin & $\mathrm{Up}$ & 16 & $\begin{array}{c}\text { Disease involved in VIM } \\
\text { is cataract }\end{array}$ \\
\hline
\end{tabular}

\subsection{Regulatory Signature: DEGs-TFs Interaction Network}

A network-based approach was employed to construct a DEGs-TFs interaction network, to identify potential TFs involved in the modulation of the DEGs. FOXC1, GATA2, YY1, FOXL1, USF2, NFIC, NFKB1, E2F1, TFAP2A, HINFP were detected as TFs regulating DEGs (Table 4 and Figure 5).

Table 4. Post-transcriptional regulatory biomolecules identified from differentially expressed genes-transcriptional interaction networks.

\begin{tabular}{|c|c|c|c|c|c|}
\hline TFs & Description & Degree & Molecular Significance & Novelty & Reference \\
\hline FOXC1 & forkhead box C1 & 785 & $\begin{array}{l}\text { deletion or duplication of FOXC1 are } \\
\text { related with cerebellar and cerebellar } \\
\text { malformation }\end{array}$ & Novel & [28] \\
\hline GATA2 & GATA binding protein 2 & 652 & $\begin{array}{l}\text { GATA2 is involved in maintaining the } \\
\text { development of GABAergic neurons, its } \\
\text { association with development of ASD is } \\
\text { not known yet. }\end{array}$ & Novel & [29] \\
\hline YY1 & YY1 transcription factor & 413 & $\begin{array}{l}\text { both deletions and de novo point } \\
\text { mutations affecting YY1 activity trigger } \\
\text { Intellectual Disability syndrome of } \\
\text { haploinsufficiency }\end{array}$ & Novel & {$[30]$} \\
\hline FOXL1 & Forkhead Box L1 & 353 & $\begin{array}{l}\text { The role of the TF FOXL1 is not known } \\
\text { in neurodevelopmental disorder }\end{array}$ & Novel & [31] \\
\hline USF2 & $\begin{array}{l}\text { Upstream Stimulatory } \\
\text { Factor } 2\end{array}$ & 325 & $\begin{array}{l}\text { USF2 is one of the major TFs that bind } \\
\text { in brain.12 known ASD SNPs are } \\
\text { associated validated TF binding sites of } \\
\text { YY1, E2F1 and USF2 enriched in } \\
\text { neurodevelopmental and } \\
\text { neuropshiatric disorder }\end{array}$ & Known & [31] \\
\hline NFIC & Nuclear Factor I C & 305 & $\begin{array}{l}\text { highly enriched in neurodevelopmental } \\
\text { disorder, not known in ASD }\end{array}$ & Novel & [32] \\
\hline NFKB1 & $\begin{array}{l}\text { Nuclear Factor Kappa B } \\
\quad \text { Subunit } 1\end{array}$ & 297 & $\begin{array}{l}\text { identified NFKB1 play crucial role in } \\
\text { etiology of treatment refractory } \\
\text { schizophrenia in Chinese Han } \\
\text { population; not known in ASD }\end{array}$ & Novel & [33] \\
\hline E2F1 & E2F Transcription Factor 1 & 287 & $\begin{array}{l}12 \text { known ASD SNPs are associated } \\
\text { validated TF binding sites of YY1, E2F1 } \\
\text { and USF2 enriched in } \\
\text { neurodevelopmental and } \\
\text { neuropsychiatric disorder PPI network. } \\
\text { Many of these SNPs are correlated with } \\
\text { synaptic transmission. }\end{array}$ & Known & [31] \\
\hline TFAP2A & $\begin{array}{l}\text { Transcription Factor } \\
\text { AP-2 Alpha }\end{array}$ & 263 & $\begin{array}{l}\text { The role of the TF TFAP2A is not known } \\
\text { in neurodevelopmental disorder. }\end{array}$ & Novel & - \\
\hline HINFP & $\begin{array}{c}\text { Histone } \mathrm{H} 4 \\
\text { Transcription Factor }\end{array}$ & 258 & $\begin{array}{l}\text { The role of the TF TFAP2A is not known } \\
\text { in neurodevelopmental disorder. }\end{array}$ & Novel & - \\
\hline
\end{tabular}




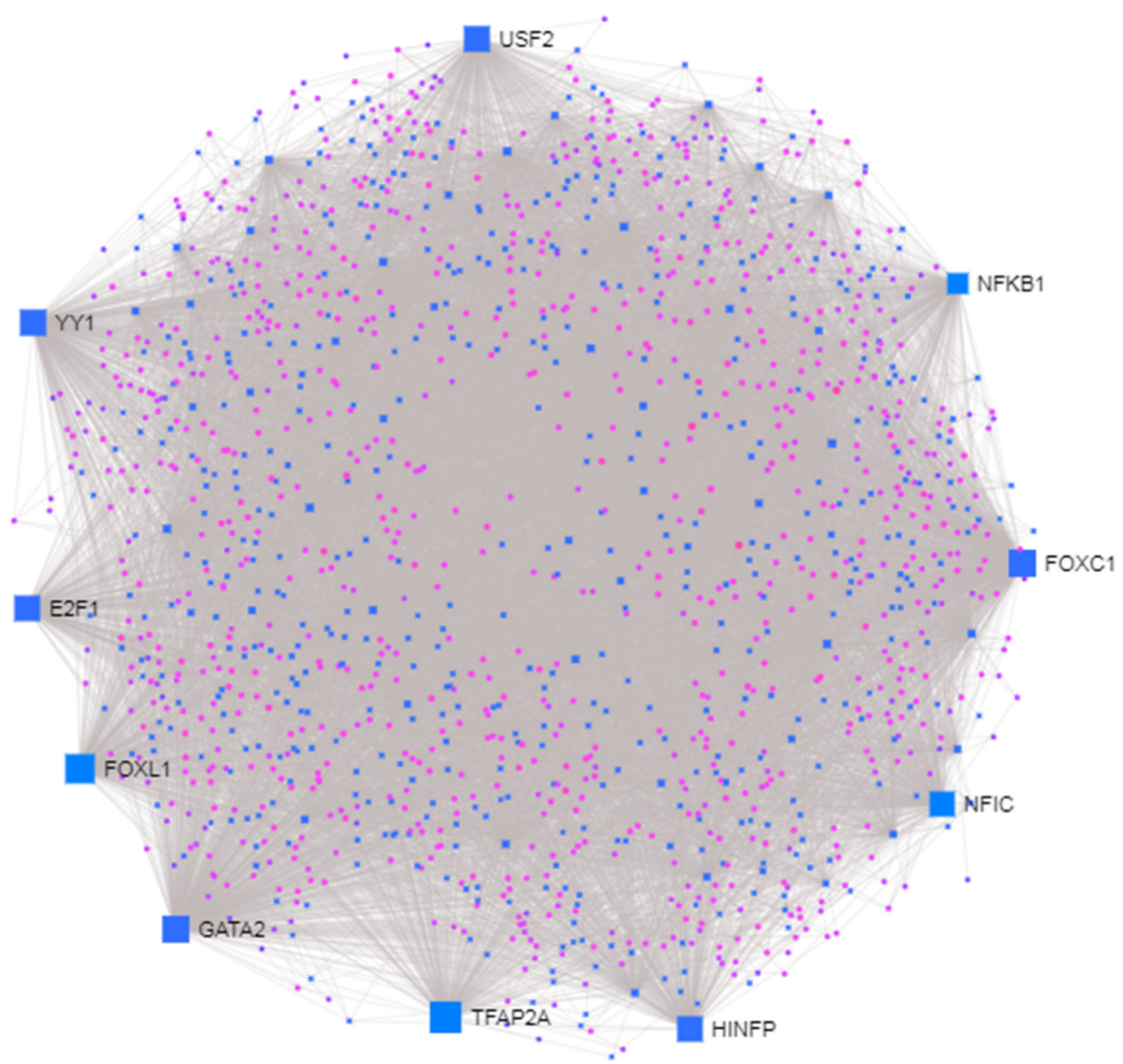

Figure 5. Network constructions of differentially expressed genes and transcription factors. Pink indicates genes and blue squares represent transcription factor. The larger blue squares show the hub transcription factor. The grey lines represent interaction.

\subsection{Cross-Validation and DEGs-Disease Association Network}

We next compared the identified 1567 DEGs with known ASD genes from SFARI database and found that 65 overlapping genes, namely, RIT2, PAK1, HCN1, CECR2, KCNC1, DNAH17, KRT26, RBFOX1, SLC9A9, OXTR, DAPP1, CAPN12, KIF14, ATP1A1, DISC1, PBA2, CADPS2, FRMPD4, ATP2B2, MSR1, PCDH15, GABRG3, GRIN2A, PTPRC, DOCK1, C4B, SAMD11, THBS1, LRP2,ERBIN, SLC7A7, STXBP1, SHOX, PLAUR, KANK1, ATP1A3, DPP4, DOCK8, FBXO40, SNAP25, RIMS3, CADPS, GABRB2, ITPR1, SEZ6L2, PCDHAC2, VSIG4, CTNNA3, SLC4A10, VDR, SYT1, CDH22, IL1R2, SCN2A, BCAS1, GFAP, PRKAR1B, SERPINE1, HLA-B, SCN8A, ITGB3, PRICKLE1, RELN, KCNJ15, ARHGEF10.

By performing a gene-disease association analysis of the meta DEGs, we found a significant association with diseases such as, Mood Disorders, Autistic Disorder, Intellectual Disability, Unipolar Depression, Mental Retardation, Low intelligence, Global developmental delay, Depressive disorder, Seizures, Bipolar Disorder, Major Depressive Disorder, Mental Depression, Epilepsy, Cognitive delay, Cerebellar Ataxia, Inflammation (Figure 6). Our data suggest that the DEGs identified in ASD may be in common with other neurodevelopmental disorders. 


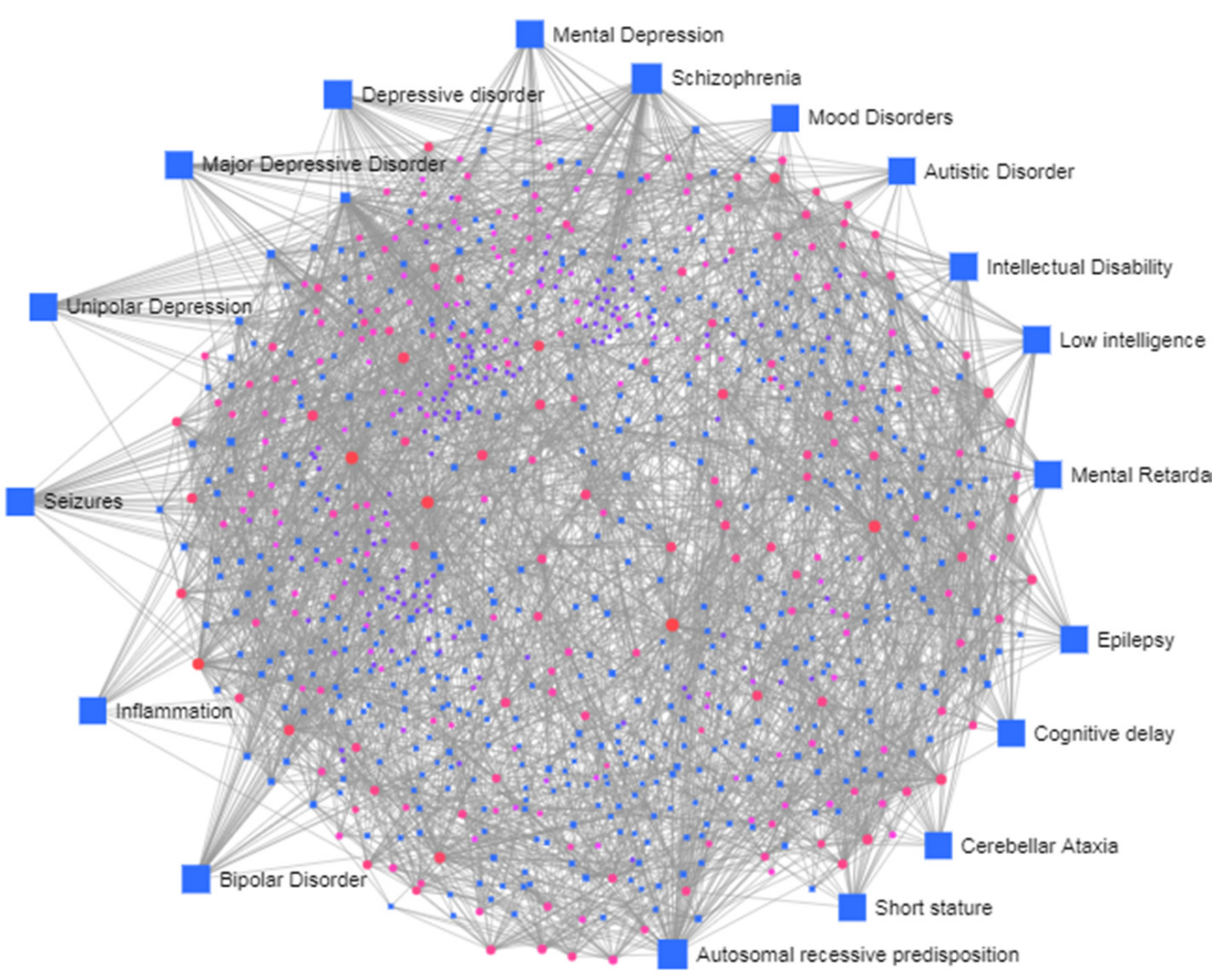

Figure 6. Network constructions of differentially expressed genes and transcription factors. Pink indicates genes and blue squares represent transcription factors. The grey lines represent interaction. The larger blue squares show important disease pathways.

\section{Discussion}

ASD is a prevalent neurodevelopmental disease that is characterized by impaired social communication and repetitive behaviors. To better understand the biological mechanisms of ASD, we decided to perform a comprehensive systems biology analysis of RNA-seq transcriptomics of the ASD brain cortex. With this aim, we performed an integrative RNA-Seq gene expression profiling in cortex to identify transcriptional gene signatures altered in 15 ASD and 15 controls (Table 1, Tables S1 and S2). From the quantitative meta-analysis, we identified 1567 differentially expressed genes (DEGs), 373 downregulated and 1194 upregulated.

Among the top DEGs, PVALB (encoding for parvalbumin) was identified as one of top DEGs (FDR $<0.05$ and $\log F C=-3.3$ ). Parvalbumin $(\mathrm{PV})$ is a calcium-binding protein expressed in a subset of GABAergic interneurons in the brain. Recently, this population of inhibitory (GABAergic) interneurons, expressing the calcium-binding protein PV (here indicated as Pvalb neurons), has attracted much attention with regard to ASD [34]. Indeed, Pvalb neurons control the coordination of neuronal networks and studies on ASD animal models have shown a reduced number of PV-immunoreactive (PV+) cells. Moreover, mice with reduced (PV+/-) or absent (PV-/-) PV expression levels show behavioral deficits similar to those observed in human ASD patients [35]. On top of that, a decreased number of Pvalb neurons has been also found in ASD post-mortem brains [36]. However, the PVALB gene has not been identified as an ASD risk gene by GWAS studies, suggesting that functional alteration of Pvalb neurons are sufficient to promote the disease, despite the presence of PVALB genetic alterations.

With the present meta-analysis, we were able to detect 235 unique DEGs, not identified by the individual studies (Table 2), supporting the increased statistical power of the meta-analysis approach [13,37]. Seven of these DEGs (PAK1, DNAH17, DOCK8, DAPP1, PCDHAC2, and ERBIN, $S L C 7 A 7)$, have been reported to be deferentially expressed in ASD. Mutation of PAK1 has been reported 
to be involved in intellectual neurodevelopmental disorder [38,39]. Genetic variants in DNAH17 gene were reported to be associated with ASD [40]. Two separate ASD cases reported a novel repeated duplication of the DAPP1 gene [41]. In another study, two SNPs within PCDHAC2 gene were associated with ASD [41].

Among the enriched pathways in ASD, we found the osteoclast differentiation pathway, which has been previously associated with ASD. Indeed ASD children have been found to have low bone density and increased risk of fractures [42-45]. Many factors play a key roles in the establishment and maintenance of bone density suggesting that common factors could be commonly involved in regulating bone density and autism [46]. In addition, osteoclast dysfunction was also observed in another neurodevelopmental/intellectual development disorder, Snyder Robinson syndrome [47]. Another pathway, the TNF signaling pathway, was also significantly deregulated in ASD. Several studies have shown increased levels of TNF in ASD subjects in brain, cerebrospinal fluids and plasma indicating the crucial roles of TNF signaling in ASD [48-50]. In line with our observation, other recent studies have highlighted the immunological involvement in the pathogenesis of ASD [51]. Cytokines mainly function as immunological response mediators, but they also have major nervous system associations. They engage in normal neuronal growth and function and may have several neurological consequences for improper actions [52]. In addition, altered cytokine levels are associated with severity symptoms of ASD [53]. In a previous study, the complement protein C3 was identified to be differentially expressed in blood of ASD versus controls [54]. Therefore, the complement pathway might be linked with inflammatory processes underlying ASD. These observations corroborated our findings suggesting that the identified pathways are crucial in development of treatment strategies in ASD, and hence can be exploited to develop new drug targets.

In the present study, we also characterized the potential TFs involved in the regulation of DEGs expression. The FOXC1 plays a role in normal development of cerebellar and posterior fossa. It has been demonstrated that deletion or duplication of $F O X C 1$ are associated with cerebellar malformation, suggesting the FOXC1 dysregulation play role in neurodevelopmental disease [28]. GATA2 is involved in maintaining the development of GABAergic neurons, movement and neuron-specific gene expression via direct action or control of other GABAergic genes [29]. However, its association with development of ASD is not known yet. $Y Y 1$ is widely expressed in brain and have role in development and neurodegeneration. Gabriele et al. showed that both deletions and de novo point mutations affecting YY1 activity trigger Intellectual Disability syndrome of haploinsufficiency with a wide variety of development and psychiatric comorbidities [30]. Twelve known ASDSNPs are associated with validated TF binding sites of $Y Y 1, E 2 F 1$ and USF2 enriched in neurodevelopmental and neuro-psychiatric disorder PPI network [31]. Many of these SNPs are correlated with synaptic transmission. GWAS study revealed genetic variants of NFIC is associated with Alzheimer's disease [32]. A genome-wide association study identified NFKB1 to play crucial role in etiology of treatment refractory schizophrenia in the Chinese Han population [33]. The roles of the TFAP2A and HINFP have not yet been described in other neurodevelopmental disorders.

The topological analysis of the protein-protein interactions is a useful approach to decode the critical signaling molecules in complex disease. The PPI analysis identified hub gene signatures, that included BAG3, CDK2, CDKN1A, EZH2, GABARAPL1, HDAC1, MYC, TP53, TRAF1 and VIM. $B A G 3$ was identified to be significantly differentially expressed in Schizophrenia by gene and pathways-based meta-analysis of microarray data [55]. Genetic variants of $B A G 3$ have been reported to be involved in Parkinson's disease [20]. A recent report revealed that genetic variants of CDKN1A have been implicated in ASD in dorsolateral prefrontal cortex region of brain [21]. Another hub protein, $E Z H 2$, is a chromatin remodeler factor and it plays essential functional roles in nervous system biology, including differentiation, neurological and cognitive development. The genetic variation of EZH2-a chromatin remodeling factors is observed in intellectual disabilities and ASD [22]. Li et al. showed aberrant expression of EZH2 in human embryonic brain suggesting a contributory role of this gene in the etiology of ASD in the Chinese population [23]. Therefore, the hub protein EZH2 may be 
implicated in ASD, in accordance with these data. Several studies have suggested a role for HDAC1 and HDAC2 in learning and memory behaviors [24]. Assessment of copy number variations suggested GABARAPL1 involved in ASD associated pathway [25]. However, differential expression has not been previously reported. However, the roles of these genes in ASD are still unclear. The role of VIM and TRAF1 in ASD pathogenesis is also not known yet. Here, we suggest that further experimental studies are warranted to establish their role as biomarkers in ASD.

Despite the tremendous significance of the present study, several limitations can be noted, in that the two RNA-Seq datasets were obtained at different times and small samples size. Additionally, the racial and ethnic background of the subjects and control did not completely match.

Our study differs significantly from other studies performed on circulating blood cells from ASD toddlers [8]. It is likely that genes that are expressed across many tissues represent major contributors to the heritability of a complex disorders, such as ASD. Given the strong genetic basis of ASD, some dysregulated developmental pathways could continually reoccur in leukocytes and thus could be studied postnatally in tissues that are easily obtained. Blood cells from ASD toddlers show perturbations in several biological processes, that include cell proliferation, differentiation, and microtubules organization, and this is in accordance with some dysregulated processes that have been described in iPSC-derived neural progenitors and neurons from individuals with ASD [8].

However, the study of blood cells cannot provide several pieces of information on dysregulated biological processes that, irrespective of the presence of genetic alterations, occur in ASD brain. One particular example is provided by parvalbumin, which is not a bona fide ASD risk gene, but is significantly altered in a population of inhibitory interneurons, recently recognized to be implicated in ASD manifestations, as previously mentioned [34-36].

\section{Conclusions}

In conclusion, the present study aimed at characterizing the whole-genome transcriptomic profile of the brain cortex from ASD patients. Our meta-analysis and systems biology analyses revealed core gene signatures as candidate biomarkers and etiopathogenetic pathways in ASD. A proteomic signature of hub genes (MYC, TP53, HDAC1, CDK2, BAG3, CDKN1A, GABARAPL1, EZH2, VIM, and TRAF1) was identified as a key driver in ASD. In general, core signatures of DEGs associated with ASD genes, including already known markers of ASD and novel hub genes, were identified. Potential implicated TFs were also discovered. The identified core gene signatures may represent candidate biomarkers and drug targets. For many of the newly identified DEGs in this study, direct associations with ASD has not previously reported. Therefore, experimental research is needed to validate these new DEGs to decipher their biological roles in ASD in order to better understand the perturbed molecular mechanisms. The present study reported novel genes and pathways in ASD, and further investigation is required for validation of hub genes in the clinical setting.

Supplementary Materials: The following are available online at http://www.mdpi.com/2076-3425/10/10/747/s1, Table S1: Demographic description of post-mortem brain tissue (GSE64018) dataset. Table S2: Demographic description of post-mortem brain tissue (GSE30573) dataset. Table S3: A complete list of differential expressed genes identified in meta-analysis of ASD vs. controls.

Author Contributions: Conceptualization, M.R.R. and T.I.; methodology, M.R.R., T.I., B.T., and M.S.; software, M.R.R., T.I., and M.S.; validation, M.R.R., T.I., B.T., and M.S.; formal analysis, M.R.R., T.I., and M.S.; investigation, M.R.R., T.I., M.S., M.C.P., R.C., A.B., P.F., F.N., M.R.I., K.Y.A., L.W., and Y.S.; resources, M.R.R., T.I., and M.S.; data curation, M.R.R., T.I., and M.S.; writing_original draft preparation, M.R.R.; writing-review and editing, M.R.R., T.I., M.C.P., R.C., A.B., P.F., F.N., M.R.I., B.T., K.Y.A., L.W., and Y.S.; visualization, M.R.R., T.I., M.S., B.T., and M.R.I.; supervision, F.N., and P.F.; project administration, F.N., and P.F.; funding acquisition, F.N. All authors have read and agreed to the published version of the manuscript.

Funding: This study was supported by current research funds 2020 of IRCCS "Centro Neurolesi Bonino-Pulejo", Messina, Italy.

Conflicts of Interest: The authors declare no conflict of interest. 


\section{References}

1. Maenner, M.J. Prevalence of Autism Spectrum Disorder Among Children Aged 8 Years-Autism and Developmental Disabilities Monitoring Network, 11 Sites, United States, 2016. MMWR Surveill. Summ. 2020, 69, 1-12. [CrossRef] [PubMed]

2. Rahman, M.R.; Islam, T.; Zaman, T.; Shahjaman, M.; Karim, M.R.; Huq, F.; Quinn, J.M.W.; Holsinger, R.M.D.; Gov, E.; Moni, M.A. Identification of molecular signatures and pathways to identify novel therapeutic targets in Alzheimer's disease: Insights from a systems biomedicine perspective. Genomics 2020, 112, 1290-1299. [CrossRef] [PubMed]

3. Rahman, M.R.; Islam, T.; Turanli, B.; Zaman, T.; Faruquee, H.M.; Rahman, M.M.; Mollah, M.N.H.; Nanda, R.K.; Arga, K.Y.; Gov, E.; et al. Network-based approach to identify molecular signatures and therapeutic agents in Alzheimer's disease. Comput. Biol. Chem. 2019, 78, 431-439. [CrossRef] [PubMed]

4. Ch'ng, C.; Kwok, W.; Rogic, S.; Pavlidis, P. Meta-analysis of gene expression in autism spectrum disorder. Autism Res. 2015, 8, 593-608. [CrossRef] [PubMed]

5. Glatt, S.J.; Tsuang, M.T.; Winn, M.; Chandler, S.D.; Collins, M.; Lopez, L.; Weinfeld, M.; Carter, C.; Schork, N.; Pierce, K. Blood-based gene expression signatures of infants and toddlers with autism. J. Am. Acad. Child Adolesc. Psychiatry 2012, 51, 934-944. [CrossRef] [PubMed]

6. Hu, V.W.; Lai, Y. Developing a predictive gene classifier for autism spectrum disorders based upon differential gene expression profiles of phenotypic subgroups. N. Am. J. Med. Sci. Boston 2013, 6.

7. Pramparo, T.; Pierce, K.; Lombardo, M.V.; Barnes, C.C.; Marinero, S.; Ahrens-Barbeau, C.; Murray, S.S.; Lopez, L.; Xu, R.; Courchesne, E. Prediction of autism by translation and immune/inflammation coexpressed genes in toddlers from pediatric community practices. JAMA Psychiatry 2015, 72, 386-394. [CrossRef]

8. Gazestani, V.H.; Pramparo, T.; Nalabolu, S.; Kellman, B.P.; Murray, S.; Lopez, L.; Pierce, K.; Courchesne, E.; Lewis, N.E. A perturbed gene network containing PI3K-AKT, RAS-ERK and WNT- $\beta$-catenin pathways in leukocytes is linked to ASD genetics and symptom severity. Nat. Neurosci. 2019, 22, 1624-1634. [CrossRef]

9. Oh, D.H.; Kim, I.B.; Kim, S.H.; Ahn, D.H. Predicting autism spectrum disorder using blood-based gene expression signatures and machine learning. Clin. Psychopharmacol. Neurosci. 2017, 15, 47. [CrossRef]

10. Forés-Martos, J.; Catalá-López, F.; Sánchez-Valle, J.; Ibáñez, K.; Tejero, H.; Palma-Gudiel, H.; Climent, J.; Pancaldi, V.; Fañanás, L.; Arango, C. Transcriptomic metaanalyses of autistic brains reveals shared gene expression and biological pathway abnormalities with cancer. Mol. Autism 2019, 10,1-16. [CrossRef]

11. Clough, E.; Barrett, T. The Gene Expression Omnibus Database. Methods Mol. Biol. 2016, 1418, 93-110.

12. Love, M.; Anders, S.; Huber, W. Differential analysis of count data-the DESeq2 package. Genome Biol. 2014, 15, 10-1186.

13. Rau, A.; Marot, G.; Jaffrézic, F. Differential meta-analysis of RNA-seq data from multiple studies. BMC Bioinform. 2014, 15, 91. [CrossRef] [PubMed]

14. Edwards, A.W.R.A. Fischer, Statistical Methods for Research Workers (1925). In Landmark Writings in Western Mathematics 1640-1940; Elsevier: Amsterdam, The Netherlands, 2005; pp. 856-870.

15. Yu, G.; Wang, L.G.; Han, Y.; He, Q.Y. clusterProfiler: An R package for comparing biological themes among gene clusters. Omi. A J. Integr. Biol. 2012, 16, 284-287. [CrossRef] [PubMed]

16. Xia, J.; Gill, E.E.; Hancock, R.E.W. NetworkAnalyst for statistical, visual and network-based meta-analysis of gene expression data. Nat. Protoc. 2015, 10, 823. [CrossRef]

17. Abrahams, B.S.; Arking, D.E.; Campbell, D.B.; Mefford, H.C.; Morrow, E.M.; Weiss, L.A.; Menashe, I.; Wadkins, T.; Banerjee-Basu, S.; Packer, A. SFARI Gene 2.0: A community-driven knowledgebase for the autism spectrum disorders (ASDs). Mol. Autism 2013, 4, 36. [CrossRef]

18. Piñero, J.; Queralt-Rosinach, N.; Bravo, A.; Deu-Pons, J.; Bauer-Mehren, A.; Baron, M.; Sanz, F.; Furlong, L.I. DisGeNET: A discovery platform for the dynamical exploration of human diseases and their genes. Database 2015, 2015.

19. Uhlén, M.; Karlsson, M.J.; Hober, A.; Svensson, A.S.; Scheffel, J.; Kotol, D.; Zhong, W.; Tebani, A.; Strandberg, L.; Edfors, F. The human secretome. Sci. Signal. 2019, 12. [CrossRef]

20. Nalls, M.A.; Blauwendraat, C.; Vallerga, C.L.; Heilbron, K.; Bandres-Ciga, S.; Chang, D.; Tan, M.; Kia, D.A.; Noyce, A.J.; Xue, A. Identification of novel risk loci, causal insights, and heritable risk for Parkinson's disease: A meta-analysis of genome-wide association studies. Lancet Neurol. 2019, 18, 1091-1102. [CrossRef] 
21. Anitha, A.; Nakamura, K.; Thanseem, I.; Yamada, K.; Iwayama, Y.; Toyota, T.; Matsuzaki, H.; Miyachi, T.; Yamada, S.; Tsujii, M. Brain region-specific altered expression and association of mitochondria-related genes in autism. Mol. Autism 2012, 3, 12. [CrossRef]

22. Ronan, J.L.; Wu, W.; Crabtree, G.R. From neural development to cognition: Unexpected roles for chromatin. Nat. Rev. Genet. 2013, 14, 347-359. [CrossRef] [PubMed]

23. Li, J.; You, Y.; Yue, W.; Yu, H.; Lu, T.; Wu, Z. Chromatin remodeling gene EZH2 involved in the genetic etiology of autism in Chinese Han population. Neurosci. Lett. 2016, 610, 182-186. [CrossRef]

24. Mahgoub, M.; Monteggia, L.M. A role for histone deacetylases in the cellular and behavioral mechanisms underlying learning and memory. Learn. Mem. 2014, 21, 564-568. [CrossRef] [PubMed]

25. Griswold, A.J.; Ma, D.; Cukier, H.N.; Nations, L.D.; Schmidt, M.A.; Chung, R.-H.; Jaworski, J.M.; Salyakina, D.; Konidari, I.; Whitehead, P.L.; et al. Evaluation of copy number variations reveals novel candidate genes in autism spectrum disorder-associated pathways. Hum. Mol. Genet. 2012, 21, 3513-3523. [CrossRef] [PubMed]

26. Chow, J.; Jensen, M.; Amini, H.; Hormozdiari, F.; Penn, O.; Shifman, S.; Girirajan, S.; Hormozdiari, F. Dissecting the genetic basis of comorbid epilepsy phenotypes in neurodevelopmental disorders. Genome Med. 2019, 11, 65. [CrossRef] [PubMed]

27. Lalani, A.I.; Zhu, S.; Gokhale, S.; Jin, J.; Xie, P. TRAF molecules in inflammation and inflammatory diseases. Curr. Pharm. Rep. 2018, 4, 64-90. [CrossRef] [PubMed]

28. Aldinger, K.A.; Lehmann, O.J.; Hudgins, L.; Chizhikov, V.V.; Bassuk, A.G.; Ades, L.C.; Krantz, I.D.; Dobyns, W.B.; Millen, K.J. FOXC1 is required for normal cerebellar development and is a major contributor to chromosome 6p25. 3 Dandy-Walker malformation. Nat. Genet. 2009, 41, 1037. [CrossRef] [PubMed]

29. Shrestha, S.; Offer, S.M. Epigenetic regulations of GABAergic neurotransmission: Relevance for neurological disorders and epigenetic therapy. Med. Epigenetics 2016, 4, 1-19. [CrossRef]

30. Gabriele, M.; Vulto-van Silfhout, A.T.; Germain, P.L.; Vitriolo, A.; Kumar, R.; Douglas, E.; Haan, E.; Kosaki, K.; Takenouchi, T.; Rauch, A. YY1 haploinsufficiency causes an intellectual disability syndrome featuring transcriptional and chromatin dysfunction. Am. J. Hum. Genet. 2017, 100, 907-925. [CrossRef]

31. Cristino, A.S.; Williams, S.M.; Hawi, Z.; An, J.Y.; Bellgrove, M.A.; Schwartz, C.E.; da F Costa, L.; Claudianos, C. Neurodevelopmental and neuropsychiatric disorders represent an interconnected molecular system. Mol. Psychiatry 2014, 19, 294-301. [CrossRef]

32. Jun, G.R.; Chung, J.; Mez, J.; Barber, R.; Beecham, G.W.; Bennet, D.A. Transethnic genome-wide scan identifies novel Alzheimer disease loci. Alzheimers Dement. 2017, 13, 727-738. [CrossRef] [PubMed]

33. Liou, Y.J.; Wang, H.H.; Lee, M.T.M.; Wang, S.C.; Chiang, H.L.; Chen, C.C.; Lin, C.H.; Chung, M.S.; Kuo, C.C.; Liao, D.L. Genome-wide association study of treatment refractory schizophrenia in Han Chinese. PLoS ONE 2012, 7. [CrossRef]

34. Filice, F.; Schwaller, B.; Michel, T.M.; Grünblatt, E. Profiling parvalbumin interneurons using iPSC: Challenges and perspectives for Autism Spectrum Disorder (ASD). Mol. Autism 2020, 11, 10. [CrossRef]

35. Wöhr, M.; Orduz, D.; Gregory, P.; Moreno, H.; Khan, U.; Vörckel, K.J.; Wolfer, D.P.; Welzl, H.; Gall, D.; Schiffmann, S.N.; et al. Lack of parvalbumin in mice leads to behavioral deficits relevant to all human autism core symptoms and related neural morphofunctional abnormalities. Transl. Psychiatry 2015, 5, e525. [CrossRef] [PubMed]

36. Hashemi, E.; Ariza, J.; Rogers, H.; Noctor, S.C.; Martínez-Cerdeño, V. The Number of Parvalbumin-Expressing Interneurons Is Decreased in the Medial Prefrontal Cortex in Autism. Cereb. Cortex 2017, 27, 1931-1943. [CrossRef] [PubMed]

37. Walker, E.; Hernandez, A.V.; Kattan, M.W. Meta-analysis: Its strengths and limitations. Cleve. Clin. J. Med. 2008, 75, 431. [CrossRef]

38. Harms, F.L.; Kloth, K.; Bley, A.; Denecke, J.; Santer, R.; Lessel, D.; Hempel, M.; Kutsche, K. Activating mutations in PAK1, encoding p21-activated kinase 1, cause a neurodevelopmental disorder. Am. J. Hum. Genet. 2018, 103, 579-591. [CrossRef] [PubMed]

39. Horn, S.; Au, M.; Basel-Salmon, L.; Bayrak-Toydemir, P.; Chapin, A.; Cohen, L.; Elting, M.W.; Graham, J.M., Jr.; Gonzaga-Jauregui, C.; Konen, O. De novo variants in PAK1 lead to intellectual disability with macrocephaly and seizures. Brain 2019, 142, 3351-3359. [CrossRef] [PubMed]

40. De Rubeis, S.; He, X.; Goldberg, A.P.; Poultney, C.S.; Samocha, K.; Cicek, A.E.; Kou, Y.; Liu, L.; Fromer, M.; Walker, S. Synaptic, transcriptional and chromatin genes disrupted in autism. Nature 2014, 515, 209-215. [CrossRef] [PubMed] 
41. Prasad, A.; Merico, D.; Thiruvahindrapuram, B.; Wei, J.; Lionel, A.C.; Sato, D.; Rickaby, J.; Lu, C.; Szatmari, P.; Roberts, W. A discovery resource of rare copy number variations in individuals with autism spectrum disorder. G3 Genes Genomes Genet. 2012, 2, 1665-1685. [CrossRef]

42. Lewis, K.E.; Sharan, K.; Takumi, T.; Yadav, V.K. Skeletal Site-specific Changes in Bone Mass in a Genetic Mouse Model for Human 15q11-13 Duplication Seen in Autism. Sci. Rep. 2017, 7, 1-8. [CrossRef] [PubMed]

43. Calarge, C.A.; Schlechte, J.A. Bone mass in boys with autism spectrum disorder. J. Autism Dev. Disord. 2017, 47, 1749-1755. [CrossRef]

44. Neumeyer, A.M.; Sokoloff, N.C.; McDonnell, E.; Macklin, E.A.; McDougle, C.J.; Misra, M. Bone microarchitecture in adolescent boys with autism spectrum disorder. Bone 2017, 97, 139-146. [CrossRef] [PubMed]

45. Ekhlaspour, L.; Baskaran, C.; Campoverde, K.J.; Sokoloff, N.C.; Neumeyer, A.M.; Misra, M. Bone density in adolescents and young adults with autism spectrum disorders. J. Autism Dev. Disord. 2016, 46, 3387-3391. [CrossRef]

46. Karasik, D.; Rivadeneira, F.; Johnson, M.L. The genetics of bone mass and susceptibility to bone diseases. Nat. Rev. Rheumatol. 2016, 12, 323. [CrossRef] [PubMed]

47. Albert, J.S.; Bhattacharyya, N.; Wolfe, L.A.; Bone, W.P.; Maduro, V.; Accardi, J.; Adams, D.R.; Schwartz, C.E.; Norris, J.; Wood, T. Impaired osteoblast and osteoclast function characterize the osteoporosis of Snyder-Robinson syndrome. Orphanet J. Rare Dis. 2015, 10, 27. [CrossRef]

48. Li, X.; Chauhan, A.; Sheikh, A.M.; Patil, S.; Chauhan, V.; Li, X.M.; Ji, L.; Brown, T.; Malik, M. Elevated immune response in the brain of autistic patients. J. Neuroimmunol. 2009, 207, 111-116. [CrossRef]

49. Ashwood, P.; Krakowiak, P.; Hertz-Picciotto, I.; Hansen, R.; Pessah, I.N.; Van de Water, J. Altered T cell responses in children with autism. Brain. Behav. Immun. 2011, 25, 840-849. [CrossRef]

50. Chez, M.G.; Dowling, T.; Patel, P.B.; Khanna, P.; Kominsky, M. Elevation of tumor necrosis factor-alpha in cerebrospinal fluid of autistic children. Pediatr. Neurol. 2007, 36, 361-365. [CrossRef]

51. Xie, J.; Huang, L.; Li, X.; Li, H.; Zhou, Y.; Zhu, H.; Pan, T.; Kendrick, K.M.; Xu, W. Immunological cytokine profiling identifies TNF- $\alpha$ as a key molecule dysregulated in autistic children. Oncotarget 2017, 8, 82390. [CrossRef]

52. Goines, P.E.; Ashwood, P. Cytokine dysregulation in autism spectrum disorders (ASD): Possible role of the environment. Neurotoxicol. Teratol. 2013, 36, 67-81. [CrossRef] [PubMed]

53. Masi, A.; Breen, E.J.; Alvares, G.A.; Glozier, N.; Hickie, I.B.; Hunt, A.; Hui, J.; Beilby, J.; Ravine, D.; Wray, J. Cytokine levels and associations with symptom severity in male and female children with autism spectrum disorder. Mol. Autism 2017, 8, 63. [CrossRef]

54. Shen, L.; Feng, C.; Zhang, K.; Chen, Y.; Gao, Y.; Ke, J.; Chen, X.; Lin, J.; Li, C.; Javed, I. Proteomics study of peripheral blood mononuclear cells (PBMCs) in autistic children. Front. Cell. Neurosci. 2019, 13, 105. [CrossRef] [PubMed]

55. Manchia, M.; Piras, I.S.; Huentelman, M.J.; Pinna, F.; Zai, C.C.; Kennedy, J.L.; Carpiniello, B. Pattern of gene expression in different stages of schizophrenia: Down-regulation of NPTX2 gene revealed by a meta-analysis of microarray datasets. Eur. Neuropsychopharmacol. 2017, 27, 1054-1063. [CrossRef] [PubMed]

Publisher's Note: MDPI stays neutral with regard to jurisdictional claims in published maps and institutional affiliations.

(C) 2020 by the authors. Licensee MDPI, Basel, Switzerland. This article is an open access article distributed under the terms and conditions of the Creative Commons Attribution (CC BY) license (http://creativecommons.org/licenses/by/4.0/). 